\title{
An assessment of chlorophyll preservation in lake sediments using multiple analytical techniques applied to the annually laminated lake sediments of Nylandssjön
}

\author{
Johan Rydberg (D) Colin A. Cooke • Julie Tolu • Alexander P. Wolfe • \\ Rolf D. Vinebrooke
}

Received: 27 September 2019/Accepted: 11 July 2020/Published online: 10 October 2020

(C) The Author(s) 2020

\begin{abstract}
Chlorophyll is frequently used as a proxy for autochthonous production in lakes. This use of chlorophyll concentrations in sediments to infer historical changes in lake primary production relies heavily on the assumption that preservation is sufficient to reflect the productivity in a meaningful way. In this study, we use a series of freeze cores from a lake with annually laminated sediments to assess how reliable down-core trends in chlorophyll are, and to what extent chlorophyll is degraded in the sediment. A
\end{abstract}

J. Rydberg $(\bowtie) \cdot$ J. Tolu

Environmental Change Assessment Group, Department of Ecology and Environmental Science, Umeå University, 90187 Umeå, Sweden

e-mail: johan.rydberg@umu.se

J. Tolu

e-mail: julie.tolu@eawag.ch

C. A. Cooke

Department of Earth and Atmospheric Sciences, University of Alberta, 1-26 Earth Sciences Building,

Edmonton, AB, Canada

e-mail: cacooke@ualberta.ca

C. A. Cooke

Environmental Monitoring and Science Division, Alberta Environment and Parks, 9888 Jasper Avenue, Edmonton, AB, Canada

J. Tolu

Department of Water Resources and Drinking Water,

Eawag, Überlandstrasse 133, 8600 Dübendorf,

Switzerland striking consistency in the down-core chlorophyll trends in four sediment cores collected in different years (1983, 1992, 2002 and 2010) shows that the sediment preserves a consistent chlorophyll signal over longer timescales. However, there are also clear signs that diagenetic processes within the sediment affect the chlorophyll concentration in sediment layers younger than $10-15$ years. This implies that care is needed when interpreting chlorophyll trends in recent sediments. Further, our data show that high-

\author{
J. Tolu \\ Department of Environmental Systems Science, ETH \\ Zurich, Universitätstrasse 16, 8092 Zurich, Switzerland
A. P. Wolfe - R. D. Vinebrooke
Department of Biological Sciences, University of Alberta,
CW 405, Biological Sciences Building, Edmonton,
$\mathrm{AB}$, Canada
e-mail: alexanderpwolfe@gmail.com
R. D. Vinebrooke
e-mail: rolf@ualberta.ca


performance liquid chromatography (HPLC) and visible reflectance spectroscopy (VRS) detect similar chlorophyll concentrations for recently dried samples. A third analytical technique, pyrolysis-gas chromatography/mass spectrometry, which provides semi-quantitative values for chlorophyll, also produce a temporal trend that is highly correlated with data from the two quantitative techniques. For samples that have been stored dried at room temperature for several years there is, however, a large discrepancy between the two quantitative techniques. The VRS method is more robust with regards to degradation during storage, while HPLC results demonstrate clear storage effects.

Keywords Sedimentary pigments - Chlorophyll · Degradation · Visible reflectance spectroscopy (VRS) · HPLC · Pyrolysis-GC/MS · Nylandssjön

\section{Introduction}

Chlorophylls (Chl) and other photosynthetic pigments are used extensively in paleolimnology and limnology as proxies for autochthonous production and algal community composition (Ady and Patoine 2016; Leavitt and Hodgson 2001; Michelutti et al. 2005; Reuss et al. 2010; Stow and Cha 2013). This use of chlorophylls as a paleolimnological proxy for total inlake primary production relies on the assumption that the amount of pigments preserved in the sediment primarily reflects production by phytoplankton and phytobenthos. However, short-term (i.e., hours to days) experimental studies have shown that chlorophyll is subjected to degradation both in the water column and in surface sediments (Carpenter et al. 1986; Cuddington and Leavitt 1999; Chen et al. 2005). This raises the question regarding how well preserved chlorophyll is in a sediment record over timescales of years to decades, i.e., timescales that are known to have a profound effect on the concentrations of, e.g., carbon and nitrogen in the sediment (Gälman et al. 2008).

Chlorophyll concentrations in sediment samples can be determined in several ways (Leavitt and Hodgson 2001). The conventional analytical approach for the quantification of chlorophyll (as well as a range of its degradation products) is to analyze sediment extracts using high-performance liquid chromatography (HPLC) coupled to an in-line spectral diode array and fluorescence detectors (Vinebrooke and Leavitt 1999). Other analytical options are to infer chlorophyll concentrations from visible reflectance spectra (VRS) recorded on the entire sediment sample using a calibration model (Michelutti et al. 2005; Wolfe et al. 2006), or to use pyrolysis-gas chromatography/mass spectrometry (Py-GC/MS). In Py-GC/MS the sediment sample is heated under an inert atmosphere (pyrolysis), which results in the production of volatile pyrolytic organic compounds that are then separated and detected by GC/MS (Ishiwatari et al. 1991; Nguyen et al. 2003).

The advantages of using VRS to reconstruct changes in sediment chlorophyll concentrations are that the analysis is non-destructive, highly reproducible, rapid (no sample pre-treatment) and inexpensive (no consumables). Michelutti and Smol (2016) have provided a thorough review and evaluation of the VRS method, which showed that the method can produce reliable results that are consistent with monitoring data. Importantly, VRS-inferred chlorophyll concentrations also include several chlorophyll degradation products, which absorb light in the same region of the VRS spectra as chlorophyll (Wolfe et al. 2006). Reasonably, this should make the VRS-inferred chlorophyll concentrations less sensitive to the effect of degradation, but this assumption has yet to be fully assessed.

In this study, we report chlorophyll concentrations determined using VRS (Michelutti et al. 2005; Wolfe et al. 2006), HPLC (Vinebrooke and Leavitt 1999) and Py-GC/MS (Tolu et al. 2015) from a unique temporal series of sediment cores from Nylandssjön (a lake with annually varved sediments; Renberg 1986). Our aim is to determine to what extent diagenetic processes affect the preservation of chlorophyll, and to assess whether the VRS method (i.e., a fast, non-destructive and comparably inexpensive analytical technique) produces similar results as the more elaborate analytical techniques (i.e., HPLC and Py-GC/MS). The sediment core series from Nylandssjön allow us to assess the diagenetic effect on chlorophyll by comparing sediment material deposited in a specific year in sediment cores collected in different years (i.e., after various degree of ageing), and has previously been used to assess the influence of diagenesis on a number of other sediment variables, e.g., carbon and nitrogen 
(Gälman et al. 2008, 2009a), mercury (Rydberg et al. 2008), iron and sulfur (Gälman et al. 2009b), lithogenic elements (Boës et al. 2011), varve thickness (Maier et al. 2013), as well as, phosphorus, rubidium, and bromine (Rydberg and Martinez Cortizas 2014).

Site description

Nylandssjön is a small dimictic, mesotrophic, lake located in northern Sweden $\left(62^{\circ} 57^{\prime} \mathrm{N}, 18^{\circ} 17^{\prime} \mathrm{E}\right.$; Fig. 1). It has a catchment consisting of a mixture of agricultural land and managed forest, and for the last 90 years it has preserved varves of extremely high quality. These varves allow us to subsample the sediment at an annual resolution. By using a series of freeze cores collected at different dates (1983 to 2010) from a 50-by-50 $\mathrm{m}$ area in the deepest part of the lake $(17.5 \mathrm{~m})$, it is possible to compare the chlorophyll

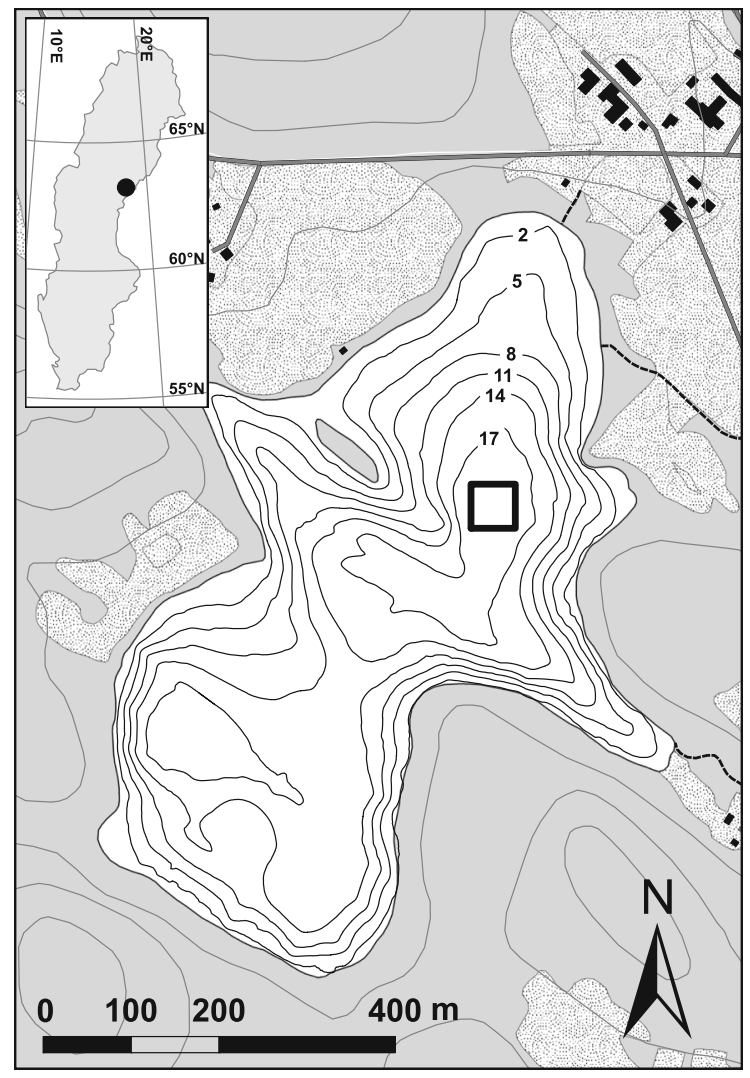

Fig. 1 Map showing the location and surroundings of Nylandssjön. The grey shaded areas represent managed forest, while stippled areas are agricultural fields. The 50-by-50 m area in the deep basin where all sediment cores have been collected is marked with a black square concentrations in "fresh" (i.e., newly deposited) sediment with the concentrations found in sediments that has aged for, e.g., 5, 10 and 15 years. However, even with an almost absolute annual resolution, the sediment cores originate from slightly different locations, and spatial heterogeneity across the deep basin might therefore have an influence on the results (Boës et al. 2011; Rydberg and Martinez Cortizas 2014).

\section{Materials and methods}

The sediment cores were collected in late winter using a freeze corer (Renberg 1981), and the freeze cores were stored at $-20{ }^{\circ} \mathrm{C}$ until subsampling. Subsampling of individual varves was done in a freezer room with a steel scalpel, and using the upper surface of the thin but distinct, black, winter layer as a divider between years. Thus, each varve represents the period from late winter to late winter (i.e., a varve-year), and the surface varve corresponds mostly to the calendar year prior to the date of core collection. All samples were freeze-dried prior to analysis. In this study, we primarily use four sediment cores that were collected in 1983, 1992, 2002 and 2010 (and subsampled in 2010). These samples (i.e., the 2010 subsampling) were directly shipped from Sweden to Canada after drying, where they were analyzed for chlorophyll during spring 2010. For the tracking of surface varves across the core series we also used samples corresponding to the 1982, 1991 and 2001 varve-years from cores collected in 1985, 1993, 1997, 2002, 2004, 2006 and 2007. Those additional samples were subsampled between 2004 and 2007 and had been stored at room temperature for up to 6 years prior to being analyzed for chlorophyll in 2010 (together with the samples from the 2010 subsampling). These older samples are hereafter referred to as the 2004 subsampling. The PyGC/MS measurements were made on a single sediment core collected in December 2005 (i.e., the surface varve represent 2005), and a set of samples that could be used to track the surface varves formed in 1979, 1982, 1988, 1991, 2001, 2003 and 2005 through time. All Py-GC/MS measurements were made during 2014, and hence, all samples used for the Py-GC/MS analyses had been stored for several years in room temperature prior to analysis. 
VRS analysis

The concentrations of VRS-inferred chlorophyll $a$ (VRS-inferred $\mathrm{Chl} a$ ) and related derivatives, including its degradation products, were determined according to the method published by Michelutti et al. (2005). In brief, the VRS spectra of dried and ground sediment samples were obtained using a FieldSpec ${ }^{\circledR}$ Pro spectroradiometer (Analytical Spectral Devices, Boulder Colorado). Based on a sample set consisting of various mixtures of sediment and algal inoculum (and for which the concentration of chlorophyll $a$ and it's isomers and degradation products had been determined by HPLC-UV/fluorescence) it was possible to establish a linear relationship between the trough area in the region $650-700 \mathrm{~nm}$ and the chlorophyll $a$ concentrations $\quad\left(\mathrm{r}^{2}=0.86\right.$, $p$ value $<0.01$; Michelutti et al. 2005). This relationship was then used to calculate the VRS-inferred Chl $a$ concentration (which includes the concentrations of both primary and degraded chlorophyll a in lake sediments) in the samples from Nylandssjön.

HPLC analysis

Quantification of chlorophyll $a$, chlorophyll $b$ and its detectable derivatives (i.e., pheophorbide and pheophytin) using the HPLC technique followed the method described by Vinebrooke and Leavitt (1999). In brief, pigments were extracted by soaking the samples in a mixture of acetone, methanol and water (80:15:5 by volume). The extracts were dried, redissolved in the injection solvent and loaded on a HPLC column for separation. Detection was made inline using fluorescence (435 and $667 \mathrm{~nm}$ ) and photodiode array $(435 \mathrm{~nm})$ detectors. Quantification was done by calibration against dilution series of authentic standards obtained from DHI Labs, Denmark. Data from the HPLC method is reported as either HPLCmeasured Chl $a$ (referring to only chlorophyll $a$ ) or HPLC-measured $\mathrm{Chl}_{\text {Sum }}$ (referring to the sum of chlorophyll $a$, chlorophyll $b$, pheophorbide and pheophytin).

\section{Pyrolysis GC/MS measurements}

In 2014, Py-GC/MS analysis was performed according to the method described by Tolu et al. (2015). In brief, $200 \pm 10 \mu \mathrm{g}$ dry sediment was pyrolyzed in a
FrontierLabs PY-2020iD oven $\left(450{ }^{\circ} \mathrm{C}\right)$ connected to an Agilent 7890A-5975C GC/MS system. All samples used for comparisons within a core or to track diagenesis across the core series were analyzed during the same session to avoid any differences introduced by variations in the measuring conditions. Peak integration and mass spectra extraction was done using a data-processing pipeline under the ' $R$ ' computational environment. Using the software 'NIST MS Search $2^{\prime}$ containing the library 'NIST/EPA/NIH 2011' and additional published spectra (Tolu et al. 2015), we identified (i) five specific pyrolytic products of chlorophylls, i.e., phytol, two phytene isomers and two phytadiene isomers (Ishiwatari et al. 1991; Nguyen et al. 2003) and (ii) prist-1-ene that have been shown to be a pyrolytic product of degraded/ processed chlorophylls (Ishiwatari et al. 1991; Nguyen et al. 2003), although also produced from pyrolysis of tocopherols (Goossens et al. 1984; Nassiry et al. 2009). The presented values are the sum of all these pyrolysis products, which has been denoted $\mathrm{Py}-\mathrm{GC} /$ MS Chl Sum. $_{\text {. }}$

Comparisons between techniques and statistical treatment

Because the three analytical techniques that were used are fundamentally different, there is a slight difference in what chlorophyll concentrations they report. The calibration model used to infer chlorophyll concentrations from the VRS-spectra in this study was calibrated against chlorophyll $a$ and its derivatives (Michelutti et al. 2005). The comparison between the VRS and HPLC methods was done both based on chlorophyll $a$ concentrations (i.e., the VRS-inferred Chl $a$ against only the chlorophyll $a$ from the HPLC method, i.e., HPLC-measured $\mathrm{Chl} a$ ) and between the VRS-inferred Chl $a$ and the sum of all chlorophylls and chlorophyll derivatives that were detected using the HPLC method (i.e., chlorophylls $a+b$, pheophorbide and pheophytin, which is denoted HPLC-measured $\left.\mathrm{Chl}_{\text {Sum }}\right)$. In this way we can assess to what extent the VRS method is sensitive to not only $\mathrm{Chl} a$, but also other types of chlorophylls (e.g., Chl $b$ ) and chlorophyll derivatives. For the Py-GC/MS data we report the signal intensities for the sum of all pyrolysis products related to chlorophylls (Py-GC/MS Chl $\mathrm{Sum}_{\text {}}$ ). Chlorophyll is used whenever referring to chlorophylls in general, i.e., not to a specific analytical 
technique or a specific type of chlorophyll or chlorophyll derivative.

All correlation analyses between the HPLC, VRSinferred and Py-GC/MS data were made as bivariate two-tailed Pearson correlations using IBM's statistical software SPSS, ver. 24 (www.spss.com). The significance level was set to 0.05 . To assess the change in chlorophyll concentrations with time, i.e., the diagenetic effect, the measured chlorophyll concentration in the sediment deposited in a specific varve-year (e.g., 1982) was tracked across the core series from when it was a newly deposited surface varve in the 1983 core and as it ages in the cores collected at later dates (e.g., 1985, 1992, 1993, 1997, 2002, 2004, 2006, 2007 and 2010). The change in chlorophyll concentration in the sediment for each of the tracked varve-years (1979, 1982, 1988, 1991, 2001, 2003 and 2005) was expressed as the percent loss compared to the chlorophyll concentration when that varve-year was a surface varve according to Eq. 1,

Loss of chlorophyll $(\%)=\frac{[C h l]_{0}-[C h l]_{T}}{[C h l]_{0}} * 100$

where $[\mathrm{Chl}]_{0}$ is the chlorophyll concentration when the sediment was newly deposited (surface varve) and $[\mathrm{Chl}]_{\mathrm{T}}$ is the chlorophyll concentration for the same varve-year in a core collected at a later date.

\section{Results}

The overall temporal trend in the VRS-inferred Chl $a$ is strikingly consistent among cores (Fig. 2). All cores show a period with low VRS-inferred Chl $a$ concentrations during the early part of the record, followed by an increase from 1982 and onwards. The two cores covering the most recent decades also both capture a distinct peak in VRS-inferred Chl $a$ centered in the mid 1990s. This temporal trend, with an initial increase and a sharp transient of elevated values between varve years 1995-2000, is also reproduced in the data obtained using the other two analytical techniques (Fig. 2). Especially the VRS and Py-GC/ MS methods produce very similar down-core trends, whereas there is more variability both between years and between cores in the data obtained using the HPLC method. Despite this consistency, there is a tendency for chlorophyll concentrations in the fresh
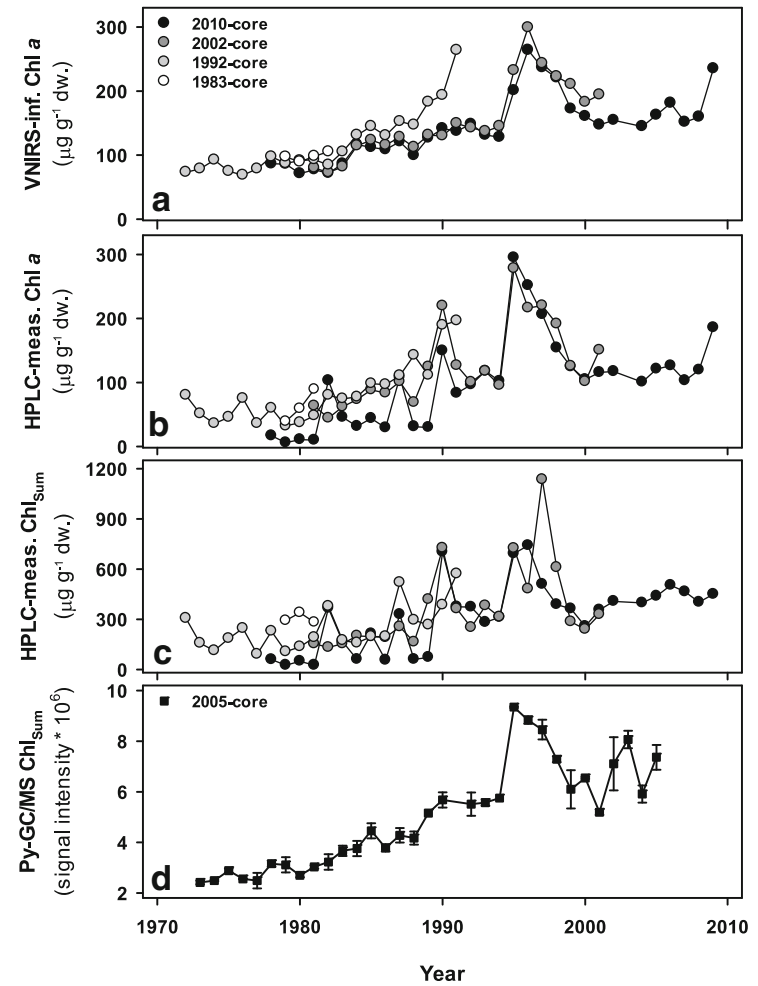

Fig. 2 Temporal trend in chlorophyll concentrations measured using different techniques. For the VRS-inferred Chl $a$ (a), HPLC-measured Chl $a$ (b) and HPLC-measured $\mathrm{Chl}_{\text {Sum }}$ (c) the analytical uncertainty can be assessed by comparing the different cores. For the semi-quantitative $\mathrm{Py}-\mathrm{GC} / \mathrm{MS} \mathrm{Chl}_{\text {Sum }}$ (d) the error bars represent the standard deviation for triplicate analysis of each sample

surface varves in each core to be higher than the chlorophyll concentration in the corresponding varveyears in cores collected at later dates (Fig. 2).

This difference becomes especially evident when each surface varve is tracked across the core series (Fig. 3). For the VRS-inferred Chl $a$ the decrease in concentration with time levels off after about 10 years at around 30, 45 and 24\% (for the 1982, 1991 and 2001 varves, respectively; Fig. 3a). For the HPLC-measured Chl $a$ the decrease with time for the 1991 varve doesn't show any signs of leveling off, and after 18 years in the sediment the HPLC-measured Chl $a$ concentration has decreased by 58 and $23 \%$, respectively for the 1991 and 2001 varves (Fig. 3b; the 1982 varve in the 1983 core was not analyzed using the HPLC method due to the low sample mass). When using HPLC-measured $\mathrm{Chl}_{\text {Sum }}$ the decrease with time in the 1991 varve appears to level off after about 


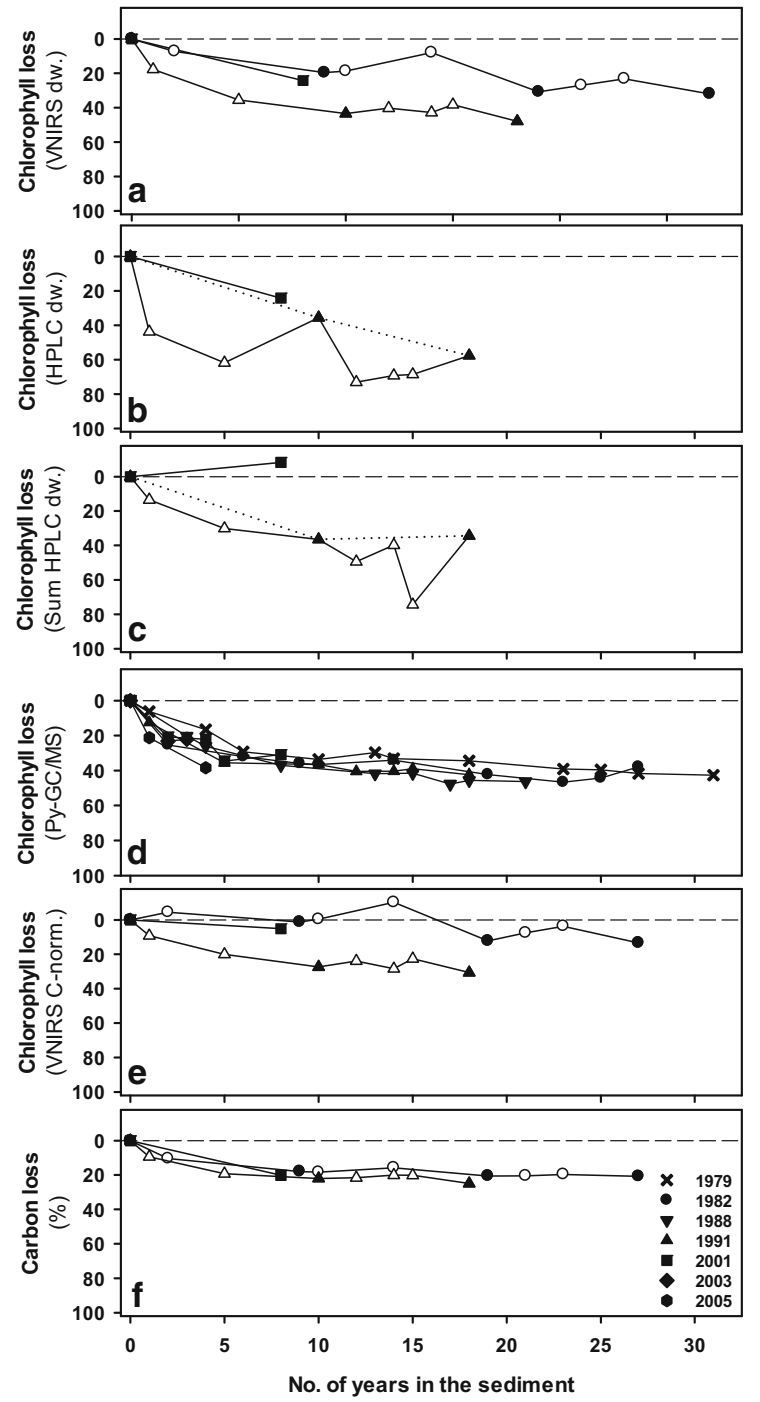

Fig. 3 The change in chlorophyll concentrations with time in the sediment, i.e., how the chlorophyll concentration in the newly deposited sediment is affected by diagenesis (the data is expressed as percent loss compared to the concentration when the varve was a surface varve). The panels represent (from top to bottom), the assessment based on the VRS-inferred Chl $a$ (a), the HPLC-measured Chl $a$ (b) the HPLC-measured $\mathrm{Chl}_{\text {Sum }}(\mathbf{c})$, and the $\mathrm{Py}-\mathrm{GC} / \mathrm{MS} \mathrm{Chl}_{\text {Sum }}$ (d), and the VRS-inferred Chl $a$ concentrations normalized to the carbon concentration (e). The lowermost (f) panel is included for reference and show the diagenetic effect on carbon concentrations (data from Gälman et al. 2008). Open and filled symbols represent the 2004 subsampling and 2010 subsampling, respectively

10 years at around $35 \%$ (Fig. 3c). For the HPLCmeasured $\mathrm{Chl} a$ there is a clear difference between samples from the two subsamplings, with the 2004 subsampling showing lower concentrations as compared to the 2010 subsampling (Fig. 3b). This difference is virtually absent in the VRS-inferred Chl $a$ and HPLC-measured $\mathrm{Chl}_{\text {Sum }}$ (Fig. 3a, c). In the Py-

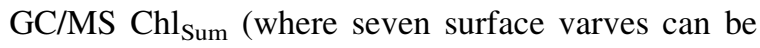
tracked as they age) there is a high degree of consistency between the different varve-years. For all varve-years that can be tracked for more than 10 years, the decreasing trend in $\mathrm{Py}-\mathrm{GC} / \mathrm{MS} \mathrm{Chl}$ Sum level off after 10-15 years at between 35 and $45 \%$ (Fig. 3d). When the VRS-inferred Chl $a$ was normalized to the carbon concentration (i.e., adjusting for the loss of carbon; Gälman et al. 2008) the decrease with time is reduced to 13, 30 and 5\% (for the 1982, 1991 and 2001 varve, respectively; Fig. 3e, f).

\section{Discussion}

The high consistency in chlorophyll concentrations between cores collected over this 27-year time period show that the chlorophyll record preserved in the sediments of Nylandssjön is highly reproducible (Fig. 2). There is also a high overall reproducibility between the VRS-inferred data and the data obtained using the two other analytical techniques (Fig. 2), with all techniques describing trends with slowly increasing chlorophyll concentrations prior to the early 1990s, a peak centered around the mid 1900s followed by a decline over the most recent time period. The interval with high chlorophyll concentrations in the mid 1990s coincides with a period when there was a reduction in dry mass accumulation rates and increase in total carbon concentrations in the sediment (Rydberg and Martinez Cortizas 2014). Together with previous studies where chlorophyll trends in sediments has been compared to monitoring data (Michelutti et al. 2010; Michelutti and Smol 2016; Stow and Cha 2013), this shows that chlorophyll can be used as a reliable proxy for assessing long-term changes in past primary production.

Although all three analytical techniques produce highly correlated concentrations (Table 1), the correlation between the VRS-inferred Chl $a$ and Py-GC/

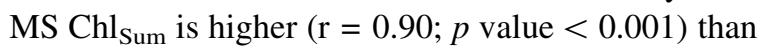
those between either the VRS-inferred Chl $a$ and HPLC-measured Chl $a(\mathrm{r}=0.84 ; p$ value $<0.001)$, the VRS-inferred Chl $a$ and HPLC-measured $\mathrm{Chl}_{\text {Sum }}$ ( $\mathrm{r}=0.70 ; p$ value $<0.001)$ or the HPLC-measured $\mathrm{Chl}_{\text {Sum }}$ and $\mathrm{Py}-\mathrm{GC} / \mathrm{MS} \mathrm{Chl}_{\text {Sum }}(\mathrm{r}=0.83 ; p$ value 
Table 1 Pearson correlation coefficients between the different types of chlorophyll data for the samples from Nylandssjön

\begin{tabular}{|c|c|c|c|c|c|}
\hline & & $\begin{array}{l}\text { VRS- } \\
\text { inferred } \\
\text { Chl } a\end{array}$ & $\begin{array}{l}\text { HPLC- } \\
\text { measured } \\
\text { Chl } a\end{array}$ & $\begin{array}{l}\text { HPLC- } \\
\text { measured } \\
\text { Chl }_{\text {Sum }}\end{array}$ & $\begin{array}{l}\mathrm{Py}-\mathrm{GC} / \mathrm{MS} \\
\mathrm{Chl}_{\text {Sum }}\end{array}$ \\
\hline \multirow[t]{2}{*}{ VRS-inferred Chl $a$} & $\mathrm{r}$ & - & $.84 *$ & $.70 *$ & $.90^{*}$ \\
\hline & $\mathrm{n}$ & - & $75^{\mathrm{a}}$ & $75^{\mathrm{a}}$ & $26^{\mathrm{b}}$ \\
\hline \multirow[t]{2}{*}{ HPLC-measured Chl $a$} & $\mathrm{r}$ & $.84 *$ & - & $.87 *$ & $.87 *$ \\
\hline & $\mathrm{n}$ & $75^{\mathrm{a}}$ & - & $75^{\mathrm{a}}$ & $26^{\mathrm{b}}$ \\
\hline \multirow[t]{2}{*}{ HPLC-measured $\mathrm{Chl}_{\text {Sum }}$} & $\mathrm{r}$ & $.70^{*}$ & $.87 *$ & - & $.83^{*}$ \\
\hline & $\mathrm{n}$ & $75^{\mathrm{a}}$ & $75^{\mathrm{a}}$ & - & $26^{\mathrm{b}}$ \\
\hline
\end{tabular}

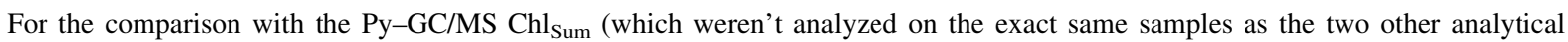
techniques) the correlations are based on average chlorophyll concentrations for each varve-year in the 1983, 1992,2002 and 2010

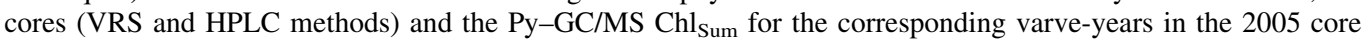

${ }^{\mathrm{a}}$ Based on the 2010 subsampling

${ }^{\mathrm{b}}$ Based on the period 1978-2005

*Correlation is significant at the 0.05 level (2-tailed)

$<0.001)$. The VRS and Py-GC/MS data also display a lower year-to-year variability as compared to the chlorophyll data from the HPLC method, and the VRS-inferred Chl $a$ is more coherent between cores (Fig. 2). This indicates that the between sample and between core variability is related to the HPLC method, possibly as a result of a larger analytical variability. Earlier studies from Nylandssjön have shown that there can be significant variability between cores, especially for elements found in low concentrations (Rydberg and Martinez Cortizas 2014), and the need for using extractions might make the HPLC method more sensitive to sample heterogeneity than the VRS and Py-GC/MS methods that requires no sample pretreatment. The difference could also relate to uncertainties introduced by sample handling (which wasn't ideal for the HPLC method).

When tracking the chlorophyll concentrations in the surface varves through the core series as the sediment material becomes older, it is apparent that there is an effect of time on the chlorophyll concentrations in the sediment of Nylandssjön (Fig. 3). For the VRS-inferred Chl $a$ there is a decrease by 30 and $45 \%$ over the initial 10-15 years for the 1982 and 1991 varve, respectively (Fig. 3). The higher loss in the 1991 varve could potentially be a result of the higher initial VRS-inferred Chl $a$ concentration in this varveyear as compared to the 1982 varve (264 and $105 \mu \mathrm{g}$ Chl $a \mathrm{~g}^{-1} \mathrm{dw}$, respectively). However, no such difference between the 1982 and 1991 varves can be seen in the Py-GC/MS Chl ${ }_{\text {Sum }}$ where both decrease by about $40 \%$.

For the HPLC-measured Chl $a$, the loss with time in the 1991 varve is higher as compared to the VRS method $(58 \%)$. When using the HPLC-measured $\mathrm{Chl}_{\text {Sum }}$ (i.e., the sum of chlorophylls $(a+b)$, pheophorbides, and pheophytins) the effect of time in the sediment is less pronounced (34\%), and the decrease is more in line with the loss in the VRSinferred Chl $a$ and Py-GC/MS Chl Sum. This supports $_{\text {S }}$ the earlier findings that the VRS method does also include the chlorophyll degradation products in the inferred chlorophyll concentrations (Michelutti et al. 2005; Michelutti and Smol 2016), but it also shows that even if we do consider the degradation products (either by analyzing them directly using the HPLC and Py-GC/MS methods, or indirectly using the VRS method)) there is a clear diagenetic effect on the chlorophyll concentrations in the sediment. Here, a potential explanation involves how chlorophyll can ultimately degrade into colorless compounds (Krautler 2008), rendering it undetectable using the VRS and HPLC methods. If the chlorophyll concentrations are normalized against the carbon concentration, which is a common practice when expressing pigment data (Leavitt and Hodgson 2001), the effect of diagenesis becomes smaller, but it is still noticeable. For example, if the VRS-inferred Chl $a$ is normalized against the carbon concentrations there is still a decrease of $13-30 \%$ because chlorophyll has a higher loss rate 
than carbon, which decrease by $20-25 \%$ over the first 10-15 years (Fig. 3; Gälman et al. 2008). This would indicate that, at least in Nylandssjön, chlorophyll degradation is faster than the degradation of the bulk organic material.

That the VRS method is less sensitive to the effects of degradation is also indicated by the distinct difference between the VRS-inferred Chl $a$ and HPLC-measured Chl $a$ for the samples from the 2004 subsampling (i.e., samples that had been stored dried at room temperature for up to 6 years prior to chlorophyll analyses; Fig. 3). For the VRS-inferred $\mathrm{Chl} a$, these samples plot along the same trend as the recently dried samples from the 2010 subsampling, whereas for the HPLC-measured Chl $a$, the 2004 subsampling give much lower concentrations. This is most likely an effect of degradation of chlorophyll during sample storage, and again, if we also make the comparison between the VRS-inferred Chl $a$ and the HPLC-measured $\mathrm{Chl}_{\text {Sum }}$ the discrepancy between the analytical techniques more or less disappear. The effect of storage can also be seen as a weaker correlation between the VRS-inferred Chl $a$ and HPLC-measured Chl $a$ when including the samples from the 2004 subampling (Fig. 4; $r=0.84$, $p$ value $<0.001, \mathrm{n}=75$ and $\mathrm{r}=0.81, p$ value $<0.001, \mathrm{n}=84$ for the 2010 subsampling and all samples, respectively). For the samples from the 1982 varve (i.e., a period with low chlorophyll concentrations) the difference between the two analytical techniques is small, but for the 1991 varve, when chlorophyll concentrations in newly dried samples were twice as high as during the 1980s, there is a clear difference with VRS method giving higher values. If the correlation analyses are made based on HPLC-measured $\mathrm{Chl}_{\text {Sum }}$, it does not make any difference whether the samples from the 2004 subsampling are included or not ( $\mathrm{r}$-values for both correlations were 0.70 and the $p$-values are $<0.001)$. Together this highlights that HPLC analyses should always be done on recently freeze-dried samples (Reuss and Conley 2005), but it also suggests that the VRS method produce reliable data also from archived samples that have been stored at room temperature for several years.

Finally, it should be recognized that this study builds on the tracking of two to seven surface varves from a single, relatively small and shallow (17 m deep), mesotrophic lake in the boreal region. Hence, it is the direction of the diagenetic change in chlorophylls, and not the absolute magnitude or duration, that carry the primary message of this work. For other types of lakes (e.g., eutrophic, oligotrophic, tropical, arctic, deep or large), chlorophyll degradation might be either a smaller or a more pronounced issue. It is therefore imperative to always take great care when interpreting recent trends in sediment chlorophyll concentrations in lake sediments. This becomes

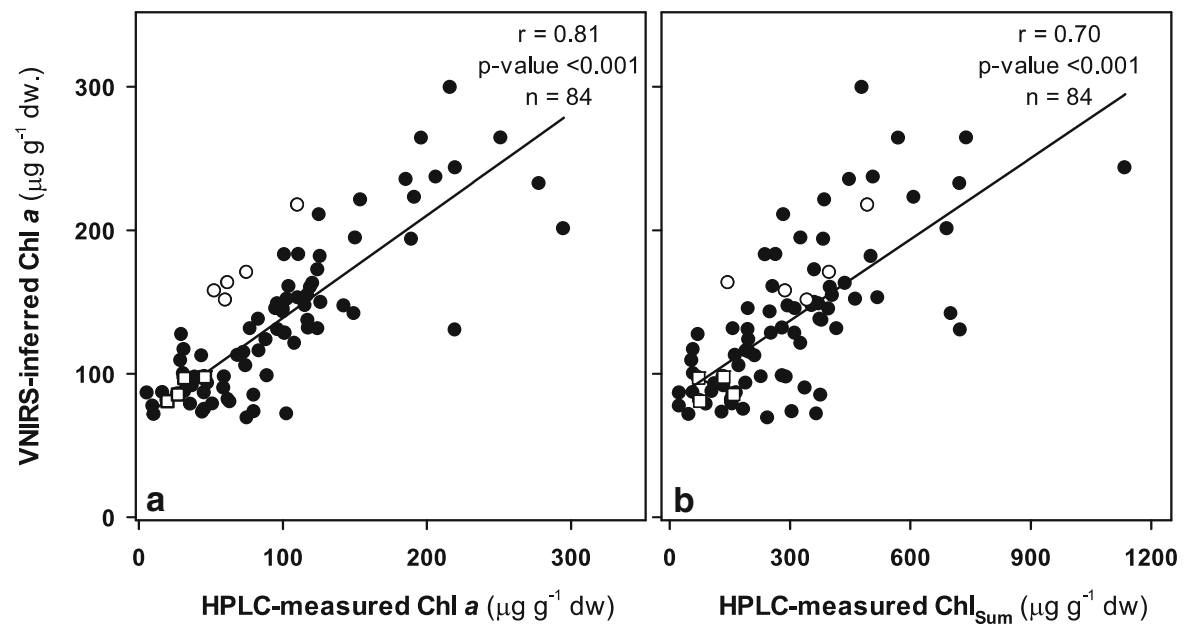

Fig. 4 The correlations between the VRS-inferred Chl $a$ and HPLC-measured Chl $a$ (a), and the VRS-inferred Chl $a$ concentrations against the HPLC-measured $\mathrm{Chl}_{\text {Sum }}(\mathbf{b})$. Samples from the 2004 and 2010 subsamplings are represented by open and filled symbols, respectively. The samples from the 1982 varve is represented by open squares, while the 1991 varve samples are represented by open circles. The regression lines correspond to the entire data set, i.e., both the 2004 and 2010 subsamplings 
particularly true for sites removed from nutrient pointsources, where it is typically necessary to compare the chlorophyll record with additional, supporting, proxies before using it as a first-order index of eutrophication (Michelutti et al. 2005; Wolfe et al. 2013).

\section{Conclusions}

Three main conclusions can be drawn from our assessment. First, the generally good consistency for the deeper sections of the down-core profiles in sediment cores of different age shows that the sediments of Nylandssjön preserve a reliable longterm chlorophyll signal that can be used for paleolimnological reconstructions. However, there is also a clear effect of diagenesis on the chlorophyll concentrations during the initial years after the formation of a specific varve. This diagenetic effect is less pronounced when taking into account chlorophyll degradation products, either by using the VRS method or by including also the chlorophyll degradation products from the HPLC or Py-GC/MS measurements. Hence, even if sediment chlorophyll concentrations might be a reliable proxy for studying long-term trends in autochthonous production, it must be recognized that an increase in the uppermost section of a sediment profile could simply be an artefact of sediment diagenesis. It is also important to note that normalizing by carbon does not fully remove the effect of sediment diagenesis on the chlorophyll record. Second, the three analytical techniques produce very similar results, and hence, this study reflects the conclusion made by Michelutti and Smol (2016) that VRS is a reliable method for analyzing chlorophyll in sediment samples. Third, HPLC-measured Chl $a$ concentrations are affected by sample storage in a way that VRS-inferred data are not. This shows that the VRS method is applicable not only for recently freeze-dried sediment samples, but also for archived samples that have been stored at room temperature for several years.

Acknowledgements Open access funding provided by Umea University. We thank the Umeå Plant Science Center for making the Py-GC/MS system available to us, Junko Takahashi Schmidt for technical support in the Py-GC/MS laboratory, Mark Graham for performing the HPLC analyses, and NSERC Canada for supporting the labs of RDV and APW. We also thank Ingemar Renberg who, through his long-term commitment in building an archive of sediment cores from Nylandssjön, made this study possible. Finally, we thank the two anonymous reviewers, Associate Editor Neal Michelutti, and Co-Editor in Chief Thomas J. Whitmore for their helpful comments.

Open Access This article is licensed under a Creative Commons Attribution 4.0 International License, which permits use, sharing, adaptation, distribution and reproduction in any medium or format, as long as you give appropriate credit to the original author(s) and the source, provide a link to the Creative Commons licence, and indicate if changes were made. The images or other third party material in this article are included in the article's Creative Commons licence, unless indicated otherwise in a credit line to the material. If material is not included in the article's Creative Commons licence and your intended use is not permitted by statutory regulation or exceeds the permitted use, you will need to obtain permission directly from the copyright holder. To view a copy of this licence, visit http://creativecommons.org/licenses/by/4.0/.

\section{References}

Ady FD, Patoine A (2016) Impacts of land use and climate variability on algal communities since $\sim 1850 \mathrm{CE}$ in an oligotrophic estuary in northeastern New Brunswick, Canada. J Paleolimnol 55:151-165

Boës X, Rydberg J, Martinez-Cortizas A, Bindler R, Renberg I (2011) Evaluation of conservative lithogenic elements ( $\mathrm{Ti}$, $\mathrm{Zr}, \mathrm{Al}$, and $\mathrm{Rb}$ ) to study anthropogenic element enrichments in lake sediments. J Paleolimnol 46:75-87

Carpenter SR, Elser MM, Elser JJ (1986) Chlorophyll production, degradation, and sedimentation: implications for paleolimnology. Limnol Oceanogr 31:112-124

Chen NH, Bianchi TS, McKee BA (2005) Early diagenesis of chloropigment biomarkers in the lower Mississippi River and Louisiana shelf: implications for carbon cycling in a river-dominated margin. Mar Chem 93:159-177

Cuddington K, Leavitt PR (1999) An individual-based model of pigment flux in lakes: implications for organic biogeochemistry and paleoecology. Can J Fish Aquat Sci 56:1964-1977

Gälman V, Rydberg J, de-Luna SS, Bindler R, Renberg I (2008) Carbon and nitrogen loss rates during ageing of lake sediment: changes over 27 years studied in a varved lake sediment. Limnol Oceanogr 53:1076-1082

Gälman V, Rydberg J, Bigler C (2009a) Decadal diagenetic effects on $\mathrm{d} 13 \mathrm{C}$ and $\mathrm{d} 15 \mathrm{~N}$ studied in varved lake sediment. Limnol Oceanogr 54:917-924

Gälman V, Rydberg J, Shchukarev A, Sjöberg S, MartinezCortizas A, Bindler R, Renberg I (2009b) The role of iron and sulfur in the visual appearance of lake sediment varves. J Paleolimnol 42:141-153

Goossens H, de Leeuw JW, Schenck PA, Brassell SC (1984) Tocopherols as likely precursors of pristane in ancient sediments and crude oils. Nature 312:440-442

Ishiwatari M, Ishiwatari R, Sakashita H, Tatsumi T, Tominaga H-o (1991) Pyrolysis of chlorophyll a after preliminary heating at a moderate temperature: implications for the 
origin of prist-1-ene on kerogen pyrolysis. J Anal Applied Pyrol 18:207-218

Krautler B (2008) Chlorophyll breakdown and chlorophyll catabolites in leaves and fruit. Photochem Photobio Sci 7:1114-1120

Leavitt PR, Hodgson DA (2001) Sedimentary pigments. In: Smol JP, Birks HJB, Last WM (eds) Tracking environmental change using lake sediments, vol 3. Terrestrail, algal, and siliceous indicators. Kluwer, Dordrecht, pp 295-325

Maier DB, Rydberg J, Bigler C, Renberg I (2013) Compaction of recent varved lake sediments. GFF 135:231-236

Michelutti N, Smol JP (2016) Visible spectroscopy reliably tracks trends in paleo-production. $\mathrm{J}$ Paleolimnol 56:253-265

Michelutti N, Wolfe AP, Vinebrooke RD, Rivard B, Briner JP (2005) Recent productivity increases in arctic lakes. Geophys Res Lett 32:L19715

Michelutti N, Blais J, Cumming B, Paterson A, Rühland K, Wolfe A, Smol J (2010) Do spectrally inferred determinations of chlorophyll a reflect trends in lake trophic status? J Paleolimnol 43:205-217

Nassiry M, Aubert C, Mouzdahir A, Rontani JF (2009) Generation of isoprenoid compounds, notably prist-1-ene, via photo and autoxidative degradation of vitamin E. Org Geochem 40:38-50

Nguyen RT, Harvey HR, Zang X, van Heemst JDH, Hetényi M, Hatcher PG (2003) Preservation of algaenan and proteinaceous material during the oxic decay of Botryococcus braunii as revealed by pyrolysis-gas chromatography/mass spectrometry and 13C NMR spectroscopy. Org Geochem 34:483-497

Renberg I (1981) Improved methods for sampling, photographing and varve-counting of varved lake sediments. Boreas 10:255-258

Renberg I (1986) Photographic demonstration of the annual nature of a varve type common in N. Swedish lake-sediments. Hydrobiologia 140:93-95

Reuss N, Conley DJ (2005) Effects of sediment storage conditions on pigment analyses. Limnol Oceanogr-Methods $3: 477-487$
Reuss NS, Hammarlund D, Rundgren M, Segerstrom U, Eriksson L, Rosen P (2010) Lake ecosystem responses to holocene climate change at the subarctic tree-line in Northern Sweden. Ecosystems 13:393-409

Rydberg J, Martinez Cortizas A (2014) Geochemical assessment of an annually laminated lake sediment record from northern Sweden: a multi-core, multi-element approach. J Paleolimnol 51:499-514

Rydberg J, Gälman V, Renberg I, Lambertsson L, Martinez Cortizas A, Bindler R (2008) Assessing the stability of mercury and methylmercury in a varved lake sediment deposit. Environ Sci Technol 42:4391-4396

Stow CA, Cha Y (2013) Are chlorophyll a - total phosphorus correlations useful for inference and prediction? Environ Sci Technol 47:3768-3773

Tolu J, Gerber L, Boily J-F, Bindler R (2015) High-throughput characterization of sediment organic matter by pyrolysisgas chromatography/mass spectrometry and multivariate curve resolution: a promising analytical tool in (paleo)limnology. Anal Chim Acta 880:93-102

Vinebrooke RD, Leavitt PR (1999) Phytobenthos and phytoplankton as potential indicators of climate change in mountain lakes and ponds: a HPLC-based pigment approach. J N Am Benthol Soc 18:15-33

Wolfe AP, Vinebrooke RD, Michelutti N, Rivard B, Das B (2006) Experimental calibration of lake-sediment spectral reflectance to chlorophyll $a$ concentrations: methodology and paleolimnological validation. J Paleolimnol 36:91-100

Wolfe AP, Hobbs WO, Birks HH, Briner JP, Holmgren S, Ingólfsson O, Kaushal SS, Miller GH, Pagani M, Saros JE, Vinebrooke RD (2013) Stratigraphic expressions of the Holocene-Anthropocene transition revealed in sediments from remote lakes. Earth-Sci Rev 116:17-34

Publisher's Note Springer Nature remains neutral with regard to jurisdictional claims in published maps and institutional affiliations. 